\title{
A risk assessment model based on fuzzy logic for electricity distribution system asset management
}

\author{
Alireza Yazdani $^{\mathrm{a}^{*}}$, Shahram Shariati ${ }^{\mathrm{b}}$ and Abdolreza Yazdani-Chamzini ${ }^{\mathrm{c}}$
}

${ }^{a}$ Electrical engineering, Golpayegan University, Isfahan, Iran

${ }^{b}$ Department of Geology, Sari Branch, Islamic Azad University, Sari, Iran

${ }^{c}$ Young Researchers and Elite Club, South Tehran Branch, Islamic Azad University, Tehran, Iran

\section{H R O N I C L E}

\section{Article history:}

Received October 15, 2013

Accepted January 24, 2014

Available online

March 62014

Keywords:

Risk assessment

Fuzzy logic

Electricity distribution system

asset management

Mamdani algorithm

\begin{abstract}
A B S T R A C T
Electricity distribution systems are considered as the most critical sectors in countries because of the essentiality of power supplement security, socioeconomic security, and way of life. According to the central role of electricity distribution systems, risk analysis helps decision maker determine the most serious risk items to allocate the optimal amount of resources and time. Probability-impact (PI) matrix is one of the most popular methods for assessment of the risks involved in the system. However, the traditional PI matrix is criticized for its inability to take into account the inherent uncertainty imposed by real-world systems. On the other hand, fuzzy sets are capable of handling the uncertainty. Thus, in this paper, fuzzy risk assessment model is developed in order to assess risk and management for electricity distribution system asset protection. Finally, a comparison analysis is conducted to show the effectiveness and the capability of the new risk assessment model.
\end{abstract}

\section{Introduction}

Electricity distribution systems are known as the most key infrastructure in modern society. The management of such systems is a complex process including cost analysis, performance evaluation and risk assessment. This process takes different perspectives into account such as economic performance, quality of supply, safety and environmental impacts (Brown \& Spare, 2004; Sand et al., 2007). These aspects often lead to a conflict in the process of decision making. Electricity distribution is by definition a so-called natural monopoly. In order to prevent abuse of monopoly power, the industry is subject to extensive regulation from authorities. During the last two decades, substantial changes have taken place in the electricity distribution sectors worldwide, changing it from generally being a protected business to being exposed to efficiency requirements and benchmarking through the monopoly regulation of electricity distribution. The process has led to efficiency improvements

\footnotetext{
* Corresponding author.

E-mail addresses: alirezayazdani28@gmail.com (A. Yazdani) 
throughout the business. Motivated by these efficiency requirements, the electricity distribution companies have intensified their efforts of creating efficient ways to build competitive business units based on the regulatory authorities benchmarking practices (NVE, 2007).

However, distribution system asset management (DSAM) is a complex process comprising the lifecycle management of a large number of geographically distributed assets. The failure of one or several assets may cause system failures (power supply interruption), with negative consequences on company economy and reputation, personnel safety or the environment. However, not all assets pose the same risks given their failure and therefore, from a risk perspective, not all assets deserve the same level of attention (Catrinu \& Nordgard, 2010). Proper identification and assessment of risks are the key factors in DSAM. Generally, asset managers (AMs) in electricity distribution companies recognize the need and the challenge of adding structure and a higher degree of formal analysis into increasingly complex asset management decisions (Nordgard, 2008).

According to importance of electricity distribution systems, different models have been developed to formulate the level of risk based on the factors influencing the risk assessment. Probability-impact (PI) matrix is one of the most well-known techniques in modeling the risks imposed by the system. This technique assesses the risk as a function of two parameters: probability and impact.

On the other hand, uncertainty is a part of real-world systems that crisp or Boolean logic is not able to take into account it. The existing uncertainty is created through two factors (Markowski et al., 2009): (1) uncertainty due to physical variability, and (2) uncertainty due to lack of knowledge. However, the PI matrix is criticized for its disability in handling the uncertainty involved in the process of the risk assessment.

Fuzzy logic can take into account uncertainty and solve problems where there are no sharp boundaries and precise values. According to capability and efficiency of fuzzy logic in modeling uncertainty, this technique is employed in different aspects of risk management (Fouladgar et al., 2012). It is clear that fuzzy logic has demonstrated its capabilities and efficiencies as a practical engineering and problem-solving tool.

The main purpose of this paper is to develop a new approach based on the PI matrix and fuzzy inference system to provide a structured framework to build a more secure, safer, and more resilient electricity distribution system. To demonstrate the potential of the proposed model, the conclusions derived from the conventional method is compared with those of the proposed model.

\section{Probability-Impact (P-I) matrix}

Probability-Impact (P-I) matrix is defined as the combination of probability and impact that helps to determine which risks need detailed risk response plans (Heldman et al., 2007). P-I matrix is used to assess the relative importance of risks. P-I scores are derived for each risk by multiplying their probability scores by their impact scores (Merna \& Al-Thani, 2005). A typical PI matrix is shown in Table 1. Therefore, risk rating can be determined through Eq. (1):

Probability $\times$ Impact $=$ Risk rating.

The risks with lower probability and impact are a less serious hazard to project goals than the risks with higher probability and impact. The root of risks that can lead to events to project should be determined and appropriate reaction to reduce or limit these factors should be considered. 
Table 1

P-I risk matrix (Parker, 2005)

\begin{tabular}{|c|c|c|c|c|c|c|}
\hline \multirow{2}{*}{\multicolumn{2}{|c|}{$R=P \times I$}} & \multicolumn{5}{|c|}{ Probability } \\
\hline & & Improbable & Remote & Occasional & Probable & Frequent \\
\hline \multirow{5}{*}{$\begin{array}{l}\overrightarrow{0} \\
\tilde{\Xi} \\
\text { : }\end{array}$} & Negligible & 1 & 2 & 3 & 4 & 5 \\
\hline & Minor & 2 & 4 & 6 & 8 & 10 \\
\hline & Major & 3 & 6 & 9 & 12 & 15 \\
\hline & Critical & 4 & 8 & 12 & 16 & 20 \\
\hline & Catastrophic & 5 & 10 & 15 & 20 & 25 \\
\hline
\end{tabular}

\section{Fuzzy inference system}

\subsection{Fuzzy set theory}

The basic concept of fuzzy logic was first introduced by Zadeh (1965) to take into account the uncertainty involved in real world problems. According to the potential application of fuzzy set theory, the systems based on fuzzy sets or fuzzy systems have been advancing from both the theoretical and the practical points (Jeronymo et al., 2011). The fuzzy logic is capable of generating answers while information is imprecise, inaccurate, ambiguous, and incomplete. This logic is general form of the proposition of the Boolean logic: either $\mathrm{x}$ belongs to A or it does not. Whereas, in fuzzy logic, the degree of membership varies between 0 and 1, which 1 addresses full membership and 0 expresses non-membership (Yazdani-Chamzini \& Yakhchali, 2012). Fig. 1 schematically shows the difference between fuzzy and crisp states. This makes it one of the most successful technologies for the development of systems to control sophisticated and complex processes, in a simple and low cost manner (Jeronymo et al., 2011).

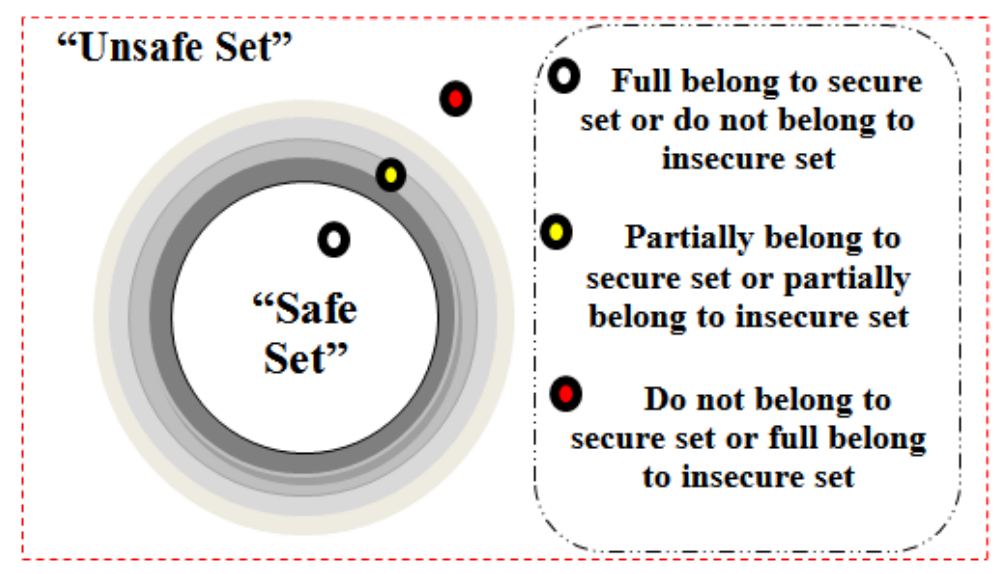

Fig. 1. Fuzzy and crisp states

Fuzzy inference is the process of formulating the mapping from a given input to an output using fuzzy logic (Jang, 1993). This process comprises membership functions, fuzzy logic operators and a set of IF-THEN rules that map input and output. The basic structure of any fuzzy inference system (see Fig. 2) contains of five main parts (Firat et al., 2009): (1) fuzzification, (2) a rule-base, containing a set of fuzzy if-then rules, (3) a data-base, which defines the membership functions of the fuzzy sets used in the fuzzy rules, (4) an inference system, combining the fuzzy rules and producing the system results, and (5) defuzzification.

There are several FISs employed in various applications of science and engineering, such as Mamdani, Takagi-Sugeno, and Tsukamoto fuzzy models. The Mamdani fuzzy model is one of the most commonly used methods in fuzzy logic for modeling many different real world problems. The 
Mamdani fuzzy models are widely used to model the dynamic structure of systems, which is due to its high power of approximation of nonlinear function from the fuzzy interpolation of regions of this function where it is described by linear models (Yen \& Langari, 1999). Differently from the TakagiSugeno fuzzy model, in which the consequents are functions of the input variables, in the Mamdani model, both antecedents and consequents of the rules are defined through fuzzy sets. In other words, the differences among FISs lie in the consequents of their rules (Ataei et al., 2:009). In this paper, the Mamdani algorithm is employed for risk assessment.

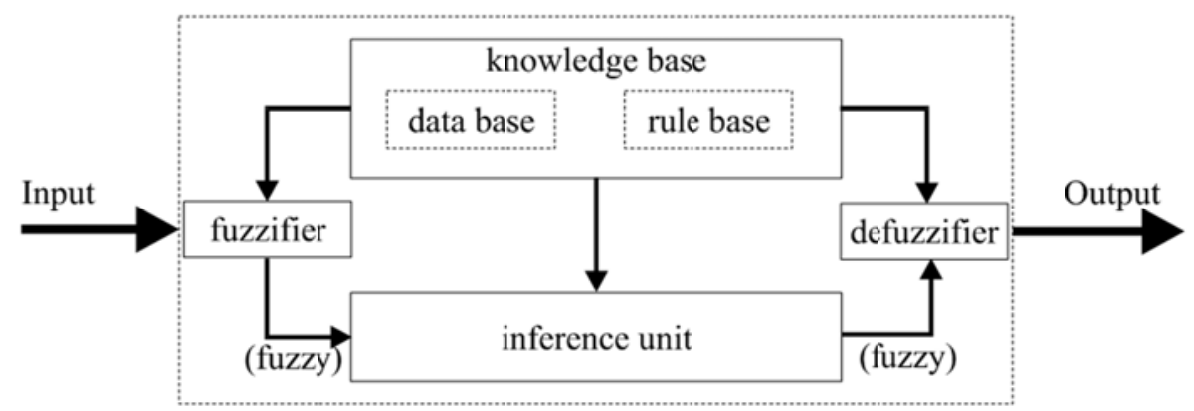

Fig. 2. Structure of FIS

\section{The proposed model for fuzzy risk assessment}

The fuzzy risk analysis method proposed in this study contains of three phases, including the probability calculation, the impact evaluation, and the risk assessment. Fuzzy logic is applied to handle the uncertainty involved in the process of modeling. A specific feature of the proposed model is an integrated model based on qualitative and quantitative techniques for power distribution system risk assessment. This can result in a complete and more accurate assessment of risks connected with hazard sources. The framework of the proposed method is schematically depicted in Fig. 3.

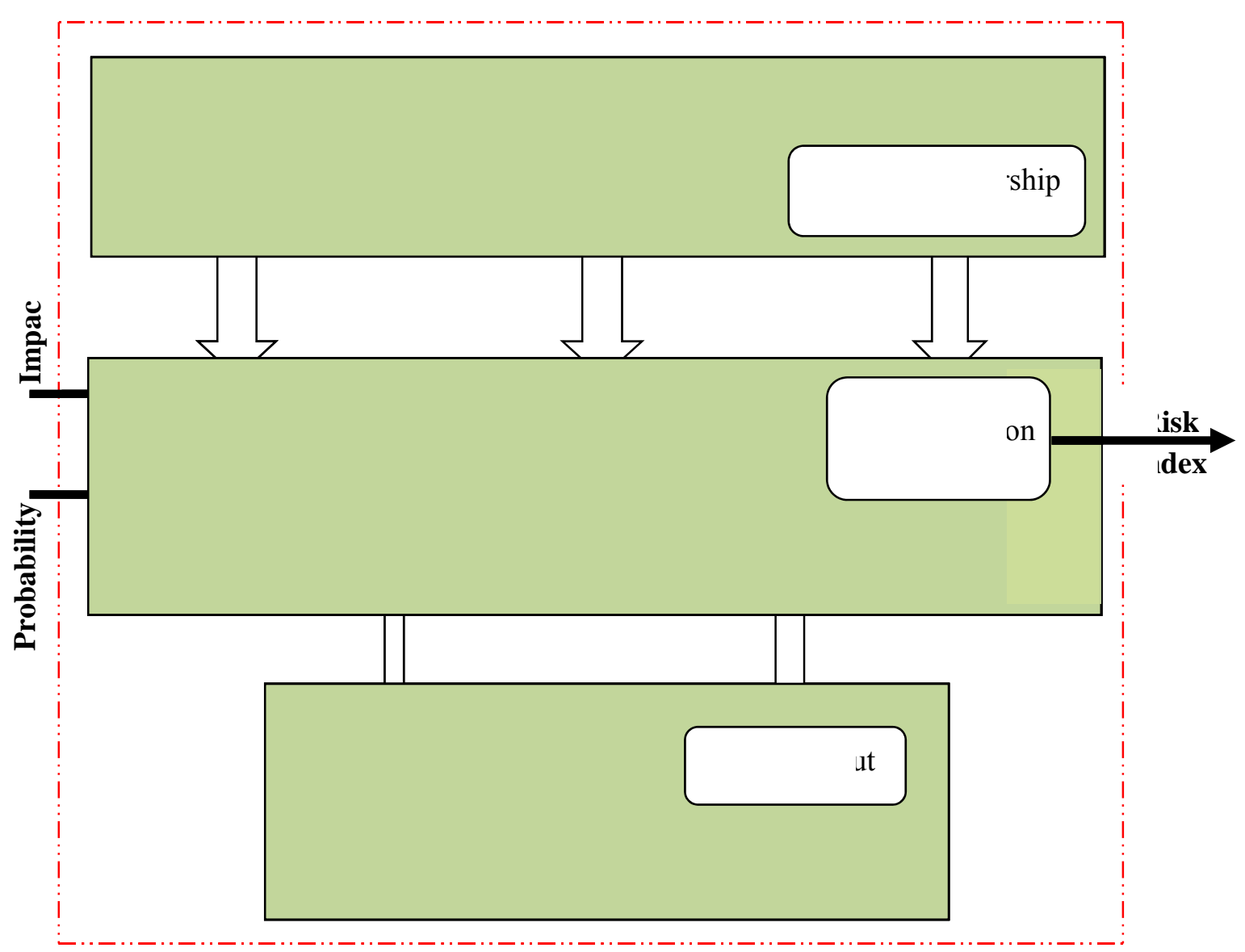

Fig. 3. Overall view of the fuzzy risk assessment system 
The first phase focuses on the overall failure probability. This phase calculates the potential for a particular failure mechanism to be active. The second phase concentrates on the overall consequence of a network failure. The last phase computes the final risk score to evaluate the level of risk in order to determine the proper mitigation strategy for activity continuity. After computing the risk values, the values are ranked in descending order. In the last step of the phase, the riskier factors are highlighted to be removed by appropriate strategies.

\section{Implementation of the proposed model}

A comparison study is illustrated to demonstrate the potential application of the proposed model for assessing the risks involved in the electricity distribution systems. A typical system is contained of several major phases that should be comprehensively studied to identify risks involved in the phases in order to make an appropriate decision for minimizing the level of risks. For achieving the aim, both system-specific risks arise from the internal environment and general risks imposed by the external environment should be considered to identify all the risks that the distribution system may encounter during the power transmission. Each part can be a potential source of miscellaneous risks.

Hence, an in-depth analysis of the electricity distribution system made it possible to identify fortyseven major dimensions of risks associated with tunneling as listed in Table 2.

\section{Table 4}

List of the risks identified

\begin{tabular}{ll}
\hline Risk category & Symbol \\
\hline Economic risk & ER \\
Safety risk & SR \\
Environmental risk & ENR \\
Quality of supply risk & QSR \\
Reputational risk & RR \\
Vulnerability risk & VR \\
Regulatory risk & RER \\
\hline
\end{tabular}

Then, fuzzy inference system is established based on the aforementioned steps as follows:

Fuzzification: The first step of the fuzzy inference system is to assign a membership value to input and output data. In this step, fuzzifier converts crisp value into fuzzy value. The inputs of the fuzzy inference system (probability and impact) must be partitioned based on their domain in a number of fuzzy sets. The structure of fuzzy inference system constructed in the paper is depicted as Fig. 4.

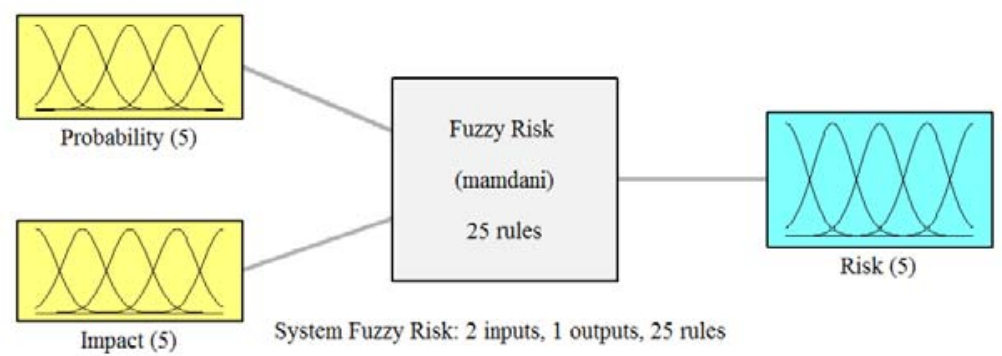

Fig. 4. Structure of the fuzzy model constructed

There are miscellaneous forms of membership function. In this paper, the Gaussian type of membership function was employed because of being the most natural (Markowski \& Mannan, 
2008), smooth and nonzero at all points (Xie, 2003). The Gaussian membership function is based on two parameters and can be represented by Eq. (2):

$\operatorname{Gaussion}(\mathrm{x} ; \mathrm{c}, \sigma)=\mathrm{e}^{-\frac{1}{2}\left(\frac{\mathrm{x}-\mathrm{c}}{\sigma}\right)^{2}}$,

where $\mathrm{c}$ and $\sigma$ are the center and width of the membership function, respectively. The authors adjusted parameter $\sigma$ so that every membership function has 50 percent overlapping. This causes the risk of introducing a "hole" in the input domain be eliminated (Xie, 2003). Figs. 5 and 6 show the membership functions for probability (P) and impact (I) respectively modeled as fuzzy set. The membership functions for output risk value are depicted in Fig. 7. As shown in Fig. 7, a scale of 0 to 5 was chosen to represent risk values as linguistic terms, such as Insignificant (IN), Tolerable (T), Substantial (SU), Significant (S), and Intolerable (INT).

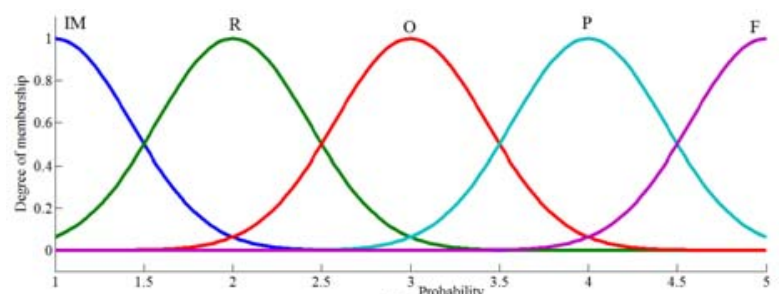

Fig. 5. Membership function for probability of occurrence

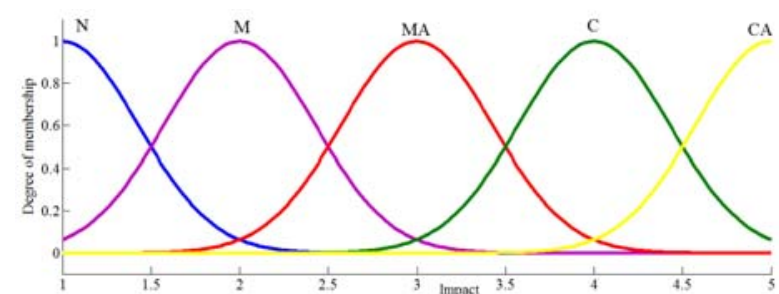

Fig. 6. Membership function for impact levels

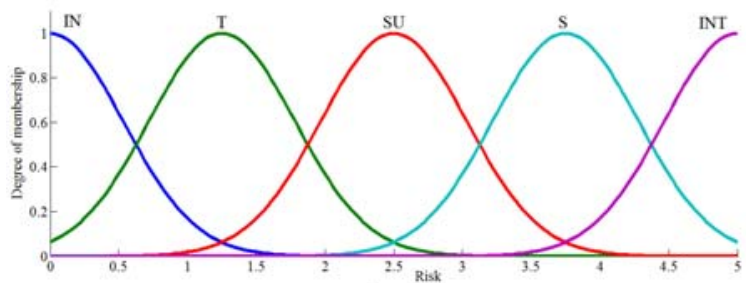

Fig. 7. Membership function for risk

Rules: There are various methods to represent knowledge in order to form date base such as Mamdani, Larsen, Takagi and Sugeno, and Tsukamoto. In this paper, the authors employed Mamdani's method due to several advantages (Cordon et al., 2001):

(1) Provides a highly flexible means to formulate, knowledge, while at the same they remain interpretable.

(2) Provides a natural framework to include expert knowledge in the form of linguistic rules,

(3) Possesses a high degree of freedom to select the most suitable fuzzification and defuzzification interface components as well as the inference method itself.

The mapping between three input parameters ( $\mathrm{P}$ and I) and risk value is constructed by the use of fuzzy if-then rules. The number of rules depends on the type of problem. We used 25 if-then rules to provide a data base. The rules are designed to follow the logic of the risk evaluator. The if-then rules of the developed system are listed in Fig. 8. 


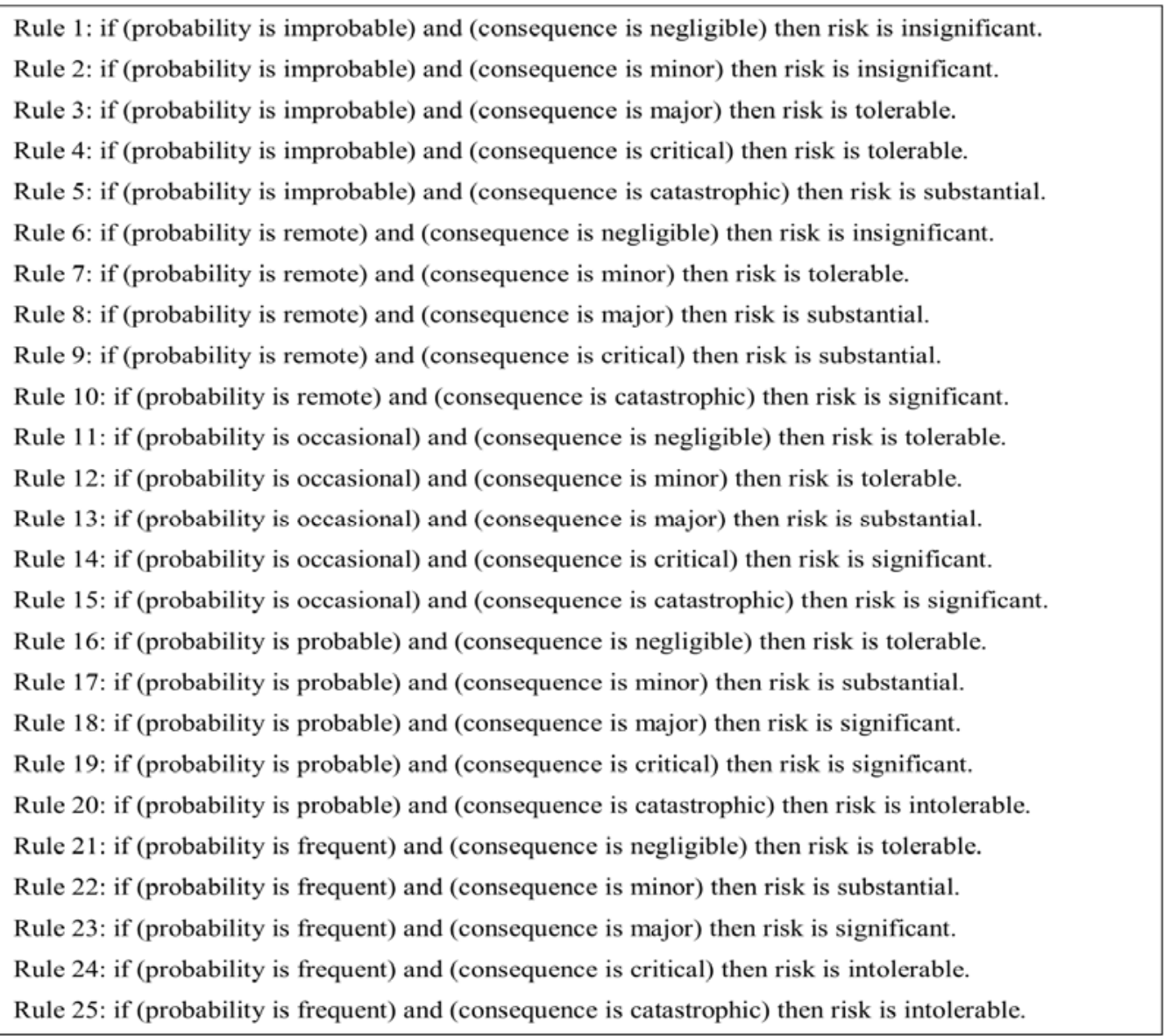

Fig. 8. List of the fuzzy if-then rules

Inference engine: Fuzzy inferences of the groups are assigned through grades of membership functions of three components. Twenty five if-then rules in order to provide a more tangible understanding of constructed system are depicted schematically in Fig. 9.

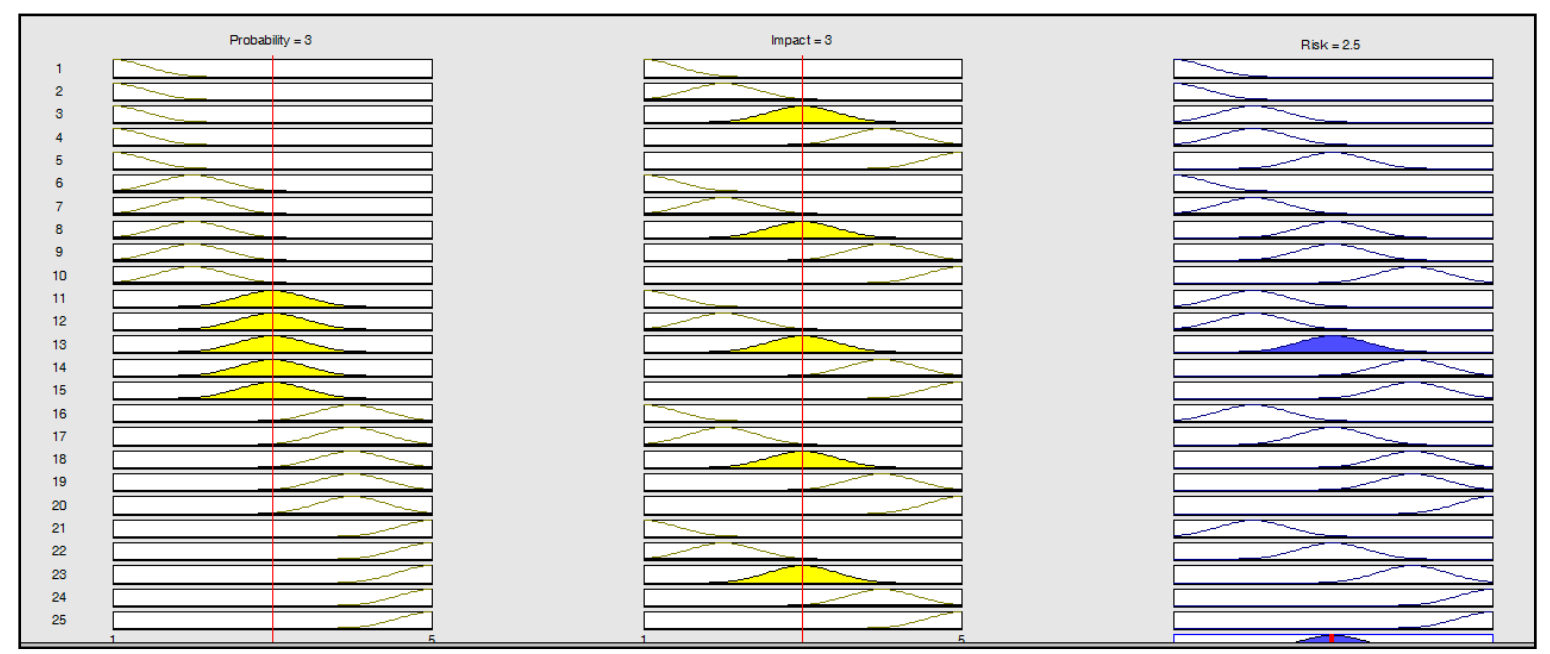

Fig. 9. Sample of rules

Fig. 10 shows the resulting control surfaces of the fuzzy inputs $\mathrm{P}$ and $\mathrm{I}$ as well as the fuzzy output risk. 


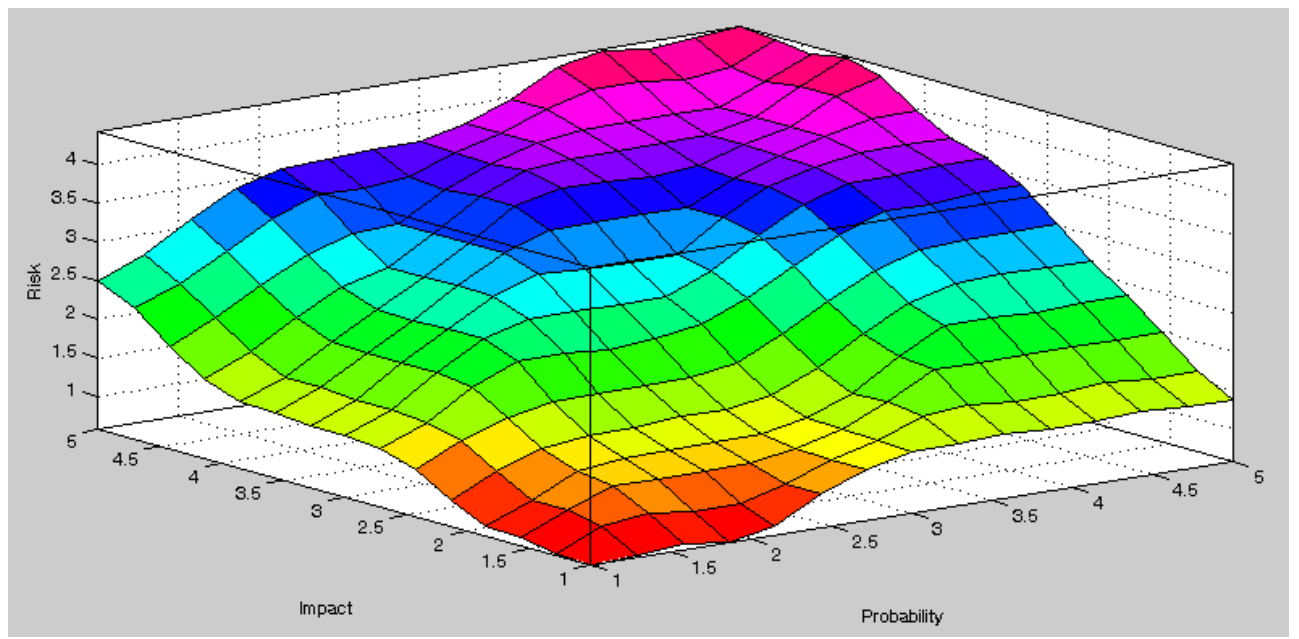

Fig. 10. Control surfaces of the inputs

Defuzzification: The last step of the fuzzy inference system is to obtain a crisp output. One of the most commonly used defuzzification method is Center of Gravity (COG) by Eq. (3):

$y^{\prime}=\frac{\int_{y} y \mu^{\prime}(y)}{\mu^{\prime}(y)}$

\section{Comparison analysis}

An assessor team consisting of six experts with high degree of knowledge in the field of risk analysis prioritizes assets in terms of $\mathrm{P}$ and I, so that; high risky asset can be connected with top priorities. Due to the difficulty in precisely assessing the risk factors and their relative importance weights, team members agree to evaluate risks by linguistic terms and then outputs are compared with the traditional PI outputs. A comparison of the results using the fuzzy PI with PI is presented in Table 2. A disadvantage of the traditional PI is that different sets of P and I may generate an identical value of risk; however, the risk implication may not necessarily be the same. For example, two assets SR and ER have values of 2, 3 and 3, 2 for P and I, respectively. Both these assets will have a risk value of 6; however, the risk implications of these two risks may be completely various. This could impose a waste of resources and time. The other disadvantage of the traditional PI ranking method is that it does not take into account the relative importance among $\mathrm{P}$ and $\mathrm{I}$. This may not be accurate in real world problems. Therefore, the outputs of fuzzy PI are more accurate. This may result a more precise, accurate and sure risk analysis for protection.

Table 2

The comparison of risk assessment results

\begin{tabular}{|c|c|c|c|c|c|c|c|c|}
\hline \multirow[t]{3}{*}{ Risk events } & \multicolumn{4}{|l|}{ Input } & \multicolumn{4}{|c|}{ Output } \\
\hline & \multicolumn{2}{|l|}{ Crisp } & \multicolumn{2}{|l|}{ Fuzzy } & \multicolumn{2}{|c|}{ Conventional method } & \multicolumn{2}{|c|}{ Proposed model } \\
\hline & Probability & Impact & Probability & Impact & Risk & Rank & Risk & Rank \\
\hline ER & 3 & 2 & 2.67 & 2.31 & 6 & 2 & 2.13 & 7 \\
\hline SR & 2 & 3 & 2.23 & 3.11 & 6 & 2 & 2.52 & 6 \\
\hline ENR & 2 & 4 & 2.41 & 4.09 & 8 & 1 & 3.11 & 2 \\
\hline QSR & 1 & 4 & 1.22 & 4.07 & 4 & 3 & 2.68 & 5 \\
\hline RR & 2 & 4 & 2.13 & 3.69 & 8 & 1 & 3.21 & 1 \\
\hline VR & 2 & 3 & 2.33 & 3.42 & 6 & 2 & 2.83 & 4 \\
\hline RER & 2 & 3 & 2.27 & 3.21 & 6 & 2 & 2.86 & 3 \\
\hline
\end{tabular}




\section{Conclusion}

The primary objective of risk analysis is to assign the most serious risk items in order to allocate the limited resources and time. A new methodology for the assessment risk of distribution systems using fuzzy set theory was developed in this work. Fuzzy sets and a fuzzy inference system are appropriate tools for handling imprecision often associated with PI components (probability and impact) data. The proposed method can solve some inherent shortcomings of the traditional PI.

The advantages of the fuzzy PI ranking technique are as follows:

(1) The input and output information in the Fuzzy PI is described as linguistic terms, which are more realistic and flexible in reflecting real situations.

(2) The results of the Fuzzy PI in comparison with the traditional PI provide more accurate, precise, and sure risk analysis for protection.

(3) In contrast with the traditional PI, the Fuzzy PI considers the relative importance among vulnerability, threat, and consequence.

\section{References}

Ataei, M., Khalokakaei, R., \& Hossieni, M. (2009). Determination of coal mine mechanization using fuzzy logic. Mining Science and Technology (China), 19(2), 149-154.

Brown, R. E., \& Spare, J. H. (2004, October). Asset management, risk, and distribution system planning. In Power Systems Conference and Exposition, 2004. IEEE PES (pp. 1681-1686). IEEE.

Catrinu, M. D., \& Nordgård, D. E. (2010). Incorporating risk analysis and multi-criteria decision making in electricity distribution system asset management.on Reliability, Risk and Safety: Theory and Applications-Briš, Guedes Soares \& Martorell (eds), Taylor \& Francis, London, 393-400.

Cordón, O. (Ed.). (2001). Genetic fuzzy systems: evolutionary tuning and learning of fuzzy knowledge bases (Vol. 19). World Scientific.

Firat, M., Turan, M. E., \& Yurdusev, M. A. (2009). Comparative analysis of fuzzy inference systems for water consumption time series prediction. Journal of hydrology, 374(3), 235-241.

Fouladgar, M. M., Yazdani-Chamzini, A., \& Zavadskas, E. K. (2012). Risk evaluation of tunneling projects. Archives of civil and mechanical engineering,12(1), 1-12.

Heldman, K., Baca, C. M., Jansen, P. M., \& Jansen, P. (2007). PMP project management professional exam study guide. John Wiley \& Sons.

Jang, J. S. (1993). ANFIS: adaptive-network-based fuzzy inference system.Systems, Man and Cybernetics, IEEE Transactions on, 23(3), 665-685.

Jeronymo, D. C., Borges, Y. C. C., \& Coelho, L. D. S. (2011). A calibration approach based on Takagi-Sugeno fuzzy inference system for digital electronic compasses. Expert Systems with Applications, 38(11), 13688-13693.

Markowski, A. S., \& Mannan, M. S. (2009). Fuzzy logic for piping risk assessment (pfLOPA). Journal of loss prevention in the process industries,22(6), 921-927.

Markowski, A. S., Mannan, M. S., \& Bigoszewska, A. (2009). Fuzzy logic for process safety analysis. Journal of Loss Prevention in the Process Industries,22(6), 695-702.

Merna, T., \& Al-Thani, F.F. (2005). Corporate Risk Management: An Organisational Perspective, John Wiley and Sons Ltd, London.

Nordgård, D. E. (2008, July). Quantitative risk assessment in distribution system maintenance management using bow-tie modeling. In 16th power systems computation conference (PSCC), Glasgow.

Nordgård, D. E., Sand, K., \& Wangensteen, I. (2009). Risk assessment methods applied to electricity distribution system asset management. Reliability, risk and safety: theory and applications'(CRC Press, 2009, vol. 1), 429-436. 
NVE (2007). Regulations covering financial and technical reporting, income caps for network operations and transmission tariffs. Reg. No. 302 of 11 March 1999 -changed as of 7 Dec 2007.

Parker, H.W. (2005). International Tunnelling Association (ITA) and risk. George Fox Seminar.

Sand, K., Gjerde, O., \& Nordgard, D.E. (2007). Current risk exposure in the distribution sector. Initial study. Trondheim, SINTEF Energy Research.

Xie, M. (2003). Fundamentals of Robotics: Linking Perception to Action. World Scientific Publishing Co Ltd, London.

Yazdani-Chamzini, A., \& Yakhchali, S. H. (2012). Tunnel Boring Machine (TBM) selection using fuzzy multicriteria decision making methods. Tunnelling and Underground Space Technology, 30, 194-204.

Yen, J., \& Langari, R., (1999). Fuzzy Logic: Intelligence, Control and Information, Prentice Hall, New Jersey, USA.

Zadeh, L. A. (1965). Fuzzy sets. Information and Control, 8(3), 338-353. 